The Open Transportation Journal
CrossMark
DOI: $10.2174 / 1874447801610010045$

\title{
Peripheral High-Speed Rail Stations in Spain
}

\author{
Carmen Bellet ${ }^{*}$ \\ Department of Geography and Sociology, University of Lleida, Spain
}

Received: April 20, 2015

Revised: June 15,2015

Accepted: September 17, 2015

\begin{abstract}
A peripheral, or city-edge, location is relatively common for new HSR stations in small and medium-sized cities and less densely populated areas. In Spain, mainly as a result of local and regional pressure, only 9 of the 35 station (Desember 2015) with HSR services are peripherally located. This paper analyses the urban planning and development local strategies that have been undertaken around peripheral HSR stations in Spain. Peripherally located HSR stations cannot be analysed as a single typology because they respond to different territorial logics and have different characteristics. However, identifying different typologies helps to understand the characteristics and territorial functions that different stations perform. The second part of the paper analyses: the local planning and development strategies employed around HSR stations which are related to their territorial contexts; the specific characteristics of each station; and the different strategies employed by stakeholders. Governance seems a fundamental issue in the case of peripheral stations because they need coordinated actions to overcome the main challenges that they face, most of which are related to their territorial integration and external accessibility.
\end{abstract}

Keywords: HSR station location, HSR and local development, HSR and urban planning, Peripheral HSR station.

\section{INTRODUCTION}

The main vocation of High Speed Rail (HSR) is to unite the cores of the largest metropolitan poles based on its speed and transport efficiency [1]. In fact the original concept of HSR was based on providing a rapid form of city to city transport (usually between metropolitan city cores) over distances of 400-600 km. At operating speeds of $250 \mathrm{~km} / \mathrm{h}$ or more, these distances between city centres could be covered in less than 3 hours: faster than the corresponding air travel services. The pressure to develop HSR was not only based on a desire for greater speed and shorter journey times, but also, in several cases (such as the Paris-Lyon route), on the need to increase the carrying capacity of key routes, to look for shorter routes and to avoid intermediate stops [2]. Such visions led to intermediate regions complaining that they would suffer all the environmental impact of a new line but receive none of the promised economic benefits, such as greater accessibility: what is known as the tunnel effect [3, 4].

As a result, new intermediate stations were developed along many of these new lines, and particularly in France and Spain in the 1990s and 2000s. Most of them were built in response to pressure from local stakeholders and accepted by rail administrators in order to extend the potential for rail market. Many intermediate stops are peripherally located in less densely populated territories with few (or unclear) urban polarities (see Fig. 1). In these contexts, new HSR stations had to be located along the line and this implied the creation of new peripheral, or city-edge, stations. In such cases, the economic logic of transport efficiency prevailed over the other needs of the existing urban/territorial structure and this meant that stations in lower ranking cities had to be moved out to the urban periphery [1,5]. However, peripherally located stations tend to give poor results in terms of traffic and the provision of services and their transport node functions tend to be quite weak. The performance of smaller intermediate stations has therefore generally been poor. Most of the examples that we detailed within the text have delivered neither the expected passenger numbers nor the

\footnotetext{
* Address correspondence to this author at the Department of Geography and Sociology, University of Lleida, Plaza Víctor Siurana,1 25003 - Lleida, Spain; Email: c.bellet@geosoc.udl.cat
} 
economic impact that was originally forecasted. This has had a cumulative effect because train operators are now reluctant to add extra stops on high-speed lines, especially when the beginning to end timings are critical in order to compete with other modes of transport such as air travel. In such cases, they feel that they must prevent the level of service falling below what could be perceived as unattractive to potential investors [6, 7].

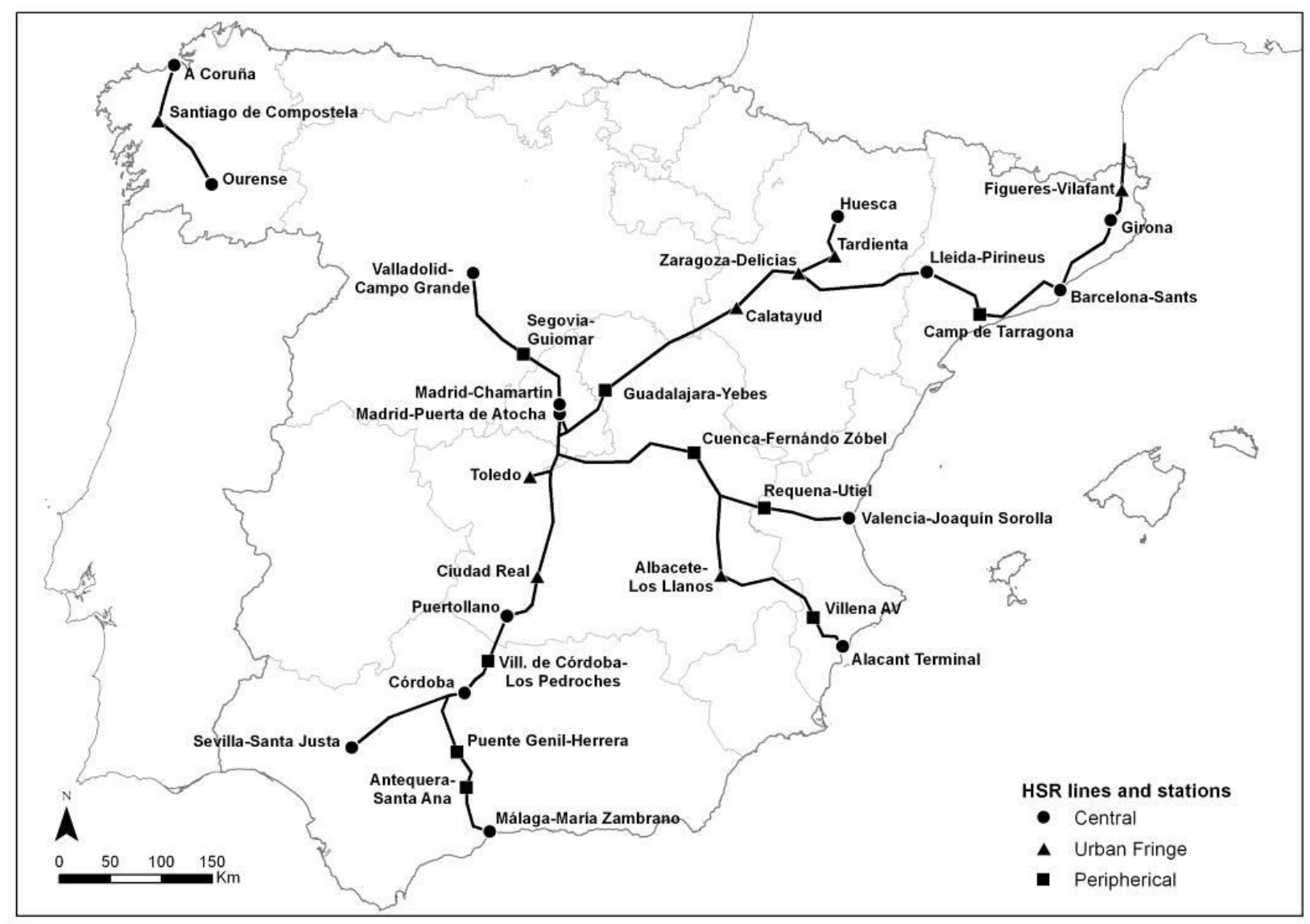

Fig. (1). Spanish HSR lines and stations (March 2015) Source: Author's own work based on information provided by ADIF.

However, as argued elsewhere, it should be noted that the concept of HSR has now changed from the original focus on city to city links [1]. The first example of this change could be seen in HSR connections to airports, reflecting the potential complementarity of rail and air travel rather than the initial focus on competition. Peripherally-located stations that are well-connected to other modes of transport, such as airports in this case, offer tremendous opportunities for other connections. The second came with the recognition that over shorter distances, of up to $200 \mathrm{~km}$, HSR could transform metropolitan labour markets and create new opportunities for commuting [8]. This mixing of different types of traffic and services gave rise to certain problems, but it was also able to offer new opportunities, particularly for intermediate stops.

When these stations are located on the urban periphery, this usually offers the advantage of making large swathes of land available for urban development. In France, HSR stations located on the urban periphery have, in some cases, favoured new property developments and activities in their immediate surroundings, especially involving advanced tertiary sector activities [9, 10]. In Spain, however, there has been little identifiable local economic development associated with many of these new stations. In fact, in many cases, the choice of a location away from the nearest urban area and poor connectivity with the local transport network have coincided with modest volumes of rail traffic and services.

\section{MATERIALS AND METHODOLOGY}

This paper analyzes the urban development plans and strategies that have been undertaken near peripherally located HSR stations in Spain. Most of these strategies and actions have been primarily related to urban development projects 
and secondarily to strategies aimed at improving accessibility and road connectivity with the new station. The methodology employed has been mainly qualitative and has focused on analysing: urban and territorial planning documentation; information obtained from local surveys and the main stakeholders (institutional planners and members of local chambers of commerce); and information obtained from the local press and field visits. This qualitative approach has been complemented with additional data to explain the main characteristics of these HSR stations and their territorial structures.

In the text, it is argued that Spain's peripherally located HSR stations cannot be analysed as a single typology because they respond to different territorial logics and perform different roles and have different characteristics as transport nodes within the rail network. The text therefore classifies peripheral stations according to their characteristics, their functions (or roles) within the railway network and the territorial contexts [7, 11, 12]. Focusing on these categories will help us to understand the different dynamisation strategies that stakeholders have planned and/or used at the local scale; this will be the main focus of the second part of this paper.

Peripheral, or city-edge, locations are relatively common for new HSR stations associated with small and mediumsized cities and less densely populated areas. In Spain, 9 of the 35 station in 2015 with HSR services have peripheral locations: Puente Genil-Herrera, Antequera-Santa Ana, Segovia, Guadalajara-Yebes, Camp de Tarragona, Cuenca, Villena, Requena-Utiel, and the newest: Villanueva de Córdoba-Los Pedroches, which was inaugurated in 2014. Most of these stations have emerged as a result of pressure from local and regional stakeholders wishing to obtain access to the HSR network [13] and only one of these, Camp de Tarragona, has also conventional rail services.

\section{THE CONTEXTS AND MAIN CHARACTERISTICS OF PERIPHERAL HSR STATIONS IN SPAIN}

As already stated, Spain's peripherally located HSR stations cannot be analysed as a single typology because they respond to different territorial logics and have different characteristics as transport nodes $[2,12,13]$. As we shall see, the territorial context is very important for understanding the role and function of each station and the main strategies that local stakeholders need to employ in each case [5, 9, 14].

The most frequent situation encountered is that of a HSR station located about 4-10 km from the nearest urban centre. This is the case at Guadalajara, Segovia and Cuenca, all of which are administrative capitals. The Camp de Tarragona and Villena stations are also peripherally located, but in multi-nuclear areas with different urban polarities, with the Camp de Tarragona area being considered an emergent metropolitan area. Puente Genil Antequera-Santa Ana, Requena-Utiel and Villanueva de Córdoba-Los Pedroches could be considered similar contexts as they involve stations located in less densely populated, predominantly rural, areas. Antequera is the station located furthest from the main urban nucleus from which it takes its name $(19 \mathrm{~km}$.), because the new station was located at a strategically important point on the HST lines from Madrid to Malaga. This strategic position explains the number of services available at this station, which hardly correspond to the number of travellers who use it [7 - 14].

Table 1. Spain's peripheral HSR stations: rail services and their territorial context (1).

\begin{tabular}{|c|c|c|c|c|c|c|}
\hline & $\begin{array}{c}\mathbf{2 0 1 1} \\
\text { Pop. Urban area } \\
(\mathbf{1})\end{array}$ & $\begin{array}{c}\text { \% Annual pop. } \\
\text { Growth 91-11 }\end{array}$ & $\begin{array}{c}\text { Municipal or } \\
\text { area } \\
\text { density pop./km2 }\end{array}$ & $\begin{array}{c}\text { Distance to } \\
\text { urban centre } \\
\text { (km) }\end{array}$ & $\begin{array}{c}\text { Rail services } \\
\text { on week days } \\
\text { (2) }\end{array}$ & $\begin{array}{c}\text { Average } \mathbf{n}^{\mathbf{0}} \text { of passengers } \\
\text { per day }\end{array}$ \\
\hline Camp de Tarragona & 382,176 & 4.9 & 1,075 & 15 & 48 & $1,688(3 \mathrm{a})$ \\
\hline Guadalajara-Yebes & 86.503 & 9.9 & 401 & 10 & 18 & $196(3 \mathrm{a})$ \\
\hline Segovia-Guiomar & 77,190 & 1.6 & 152 & 6 & 31 & $2,303(3 \mathrm{a})$ \\
\hline Puente Genil-Herrera & 36,967 & 1.7 & 97 & 7 & 23 & $271(3 \mathrm{c})$ \\
\hline Villena & 53,369 & 1.3 & 83 & 6 & 14 & $164(3 \mathrm{a})$ \\
\hline Cuenca-Fernando Zobel & 56,472 & 3.2 & 62 & 4 & 14 & $767(3 \mathrm{a})$ \\
\hline Antequera-Santa Ana & 61,938 & 1.5 & 54 & 19 & 46 & $647(3 \mathrm{c})$ \\
\hline Requena-Utiel & 31,584 & 0.9 & 23 & 5.5 & 8 & $50(3 \mathrm{~b})$ \\
\hline Los Pedroches & 55,238 & $-0,4$ & 15 & 12 & 6 & $110(3 \mathrm{~d})$ \\
\hline
\end{tabular}

Table 1 and Fig. (2) show the different roles that these stations perform as rail transport nodes and their poor results $[3,4]$. Segovia-Guiomar, with 31 rail services, is the peripheral HSR station which has the highest average number of passengers. The majority of the relations of the Segovia station are with Madrid, which is only 30 minutes away via the new HSR line and services (as opposed to the two-hour city centre to city centre trip using the conventional train service). Most of the passengers who use this service are daily commuters or people who regularly make the 25 -minute 
HSR trip to Madrid [7, 8].

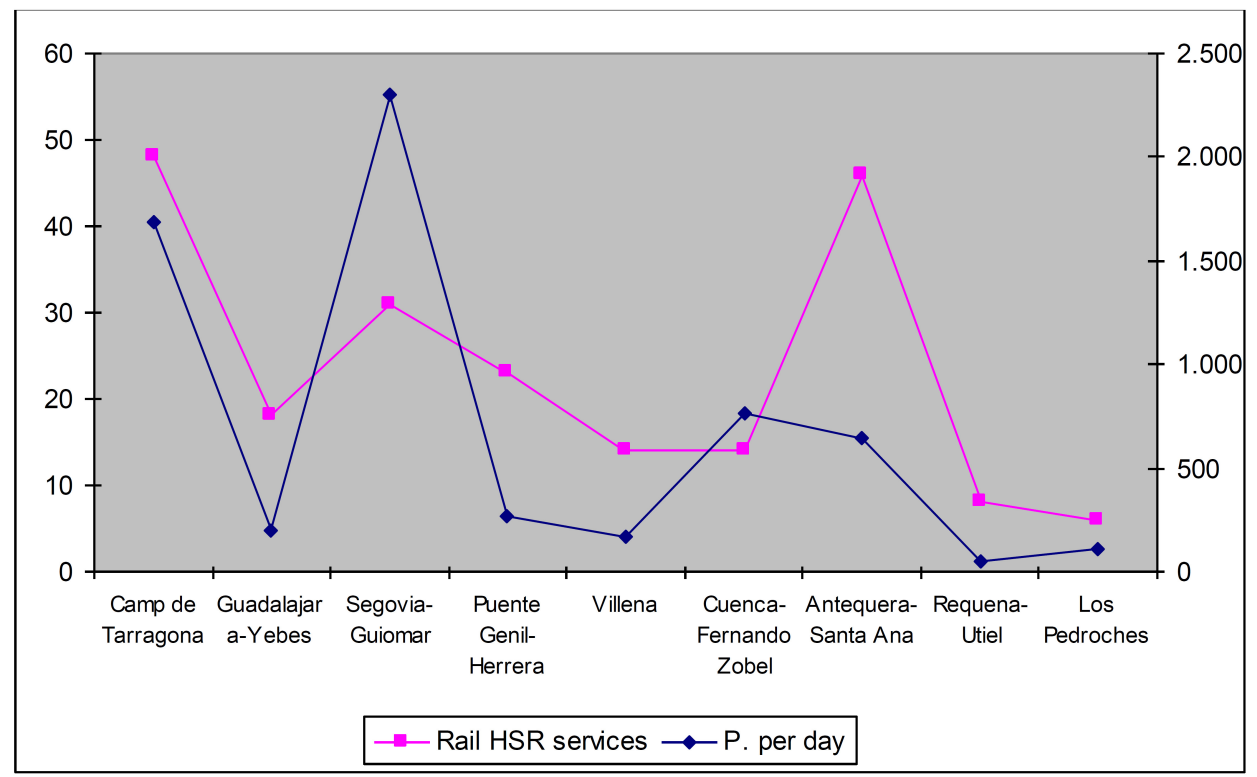

Fig. (2). HSR services and the average number of passengers received at peripheral HSR stations in Spain.

Sources: Instituto Nacional de Estadística - 1991 and 2011

1. In each case, the urban area has been delimited as follows: for Antequera: the comarca (local district) of Antequera; for Camp de Tarragona: Tarragona+Reus; for Cuenca: Cuenca; for Guadalajara: Guadalajara+Yebes; for Puente Genil: Puente Genil+Herrera; for Segovia: Segovia+La Granja; for Villena: Alt Vinalopó; for Villlanueva de Córdoba-Los Pedroches the comarca of Valle de los Pedroches.

2. For details of the rail services, see RENFE's (Spain's national rail operator) web page and daily data for February 2014.

3. For passengers per day: see data from RENFE's communication area: (3a): data for 2013; (3b): data for 2012; (3c) data for the 1st half of 2014; (3d) data for 2014

The Camp de Tarragona station, which receives 48 services per day, is used more for connections with the Madrid area and the Ebro valley than for trips to Barcelona, the nearest major metropolitan area. The conventional rail service for the 50-minute trip from the centre of Tarragona to Barcelona has a lot more trains.

Camp de Tarragona is the busiest peripheral HSR stations in terms of the number of services. This is attributable to his position and role within the rail network: it is located at a nodal point where different lines and/or rail services (conventional+HSR) converge.

The relationship between the number of services and passengers presented in the previous figure shows the poor results obtained in the cases of Guadalajara-Yebes, Puente Genil, Villena, Requena-Utiel and Los Pedroches, all of which receive fewer than 300 passengers per day. The most extreme case is that of Requena, with only 50 passengers and 8 rail services per day.

The ratio between the number of services and passengers is uneven in the cases of Segovia and Antequera. In that of Segovia, we have already mentioned the frequent and intensive use of services made by commuters travelling between Segovia and Madrid. In the case of Antequera, the large number of services that make stops at the station is mainly attributable to its nodal position at a line junction. In contrast, the station does not receive a significant number of travellers.

\section{LOCAL STAKEHOLDERS AND THE PROCESS OF HSR IMPLEMENTATION AT PERIPHERALLY LOCATED STATIONS}

The histories of HSR implantations show that the majority of peripherally located stations have appeared as a result of pressure from local or regional stakeholders. Indeed, in a few cases, pressure from the local territory has resulted in 
modification being made to the routes that had initially been planned in order to bring the railway stations in question nearer to the centres of their respective cities without excessively penalising travel times between the main destinations. The Camp de Tarragona station near Tarragona, on the Madrid-Barcelona line, provides a particularly good example of this. The trajectory of the Madrid-Barcelona railway line was pulled southwards in order to incorporate a new station which was located as close as possible to the metropolitan areas of Tarragona and Reus without having too detrimental an effect on the travel time between Madrid and Barcelona, as reflected in Fig.(1) This line modification, and the corresponding construction of Camp de Tarragona peripheral station, was the result of pressure from the Catalan government, which wanted all four of its provincial capitals (Girona, Barcelona, Tarragona and Lleida) to have HSR connections.

In such cases, obtaining a peripheral station is usually understood as a triumph for the local territory, with little importance being given to the peripheral location of the station. In the case of Segovia, once the trajectory taking the new line closer to the city had been accepted, little or no consideration was given to the precise location of the new station along this new stretch of track. As a result, the new HSR station was finally located $6 \mathrm{~km}$ outside the urban centre of Segovia, at a site that posed a number of difficulties for accessibility via road and which was $3 \mathrm{~km}$ from the conventional railway station $[13,16]$.

In other cases, local and regional stakeholders presented proposals to the Ministerio de Fomento (Ministry of Public Works) regarding the possibility of incorporating new intermediate stations located closer to the most important urban nuclei along the trajectory of already approved new railway lines (as in the case of Cuenca). In these cases, the initial trajectories were not modified, but pressure was applied to obtain extra stops.

In less densely populated territories, pressure from local stakeholders has sometimes succeeded in obtaining the incorporation of simple-structure stations (or "halts") after the trajectory of the new line had been decided. This was the case with the Requena-Utiel, Villena, Puente Genil and Villanueva de Córdoba-Los Pedroches stations. Along Spanish HSR lines, overtaking points were originally projected at intervals of 40-60 km for maintenance purposes. Local stakeholders have since sought to convert some of these points into "halts", which are quite simple structures that it would perhaps be better to refer to as "stopping points" than as stations. Most of these only have one track-side platform and few, if any, associated facilities. They have all been built on very limited budgets: less than $€ 12$ million. In fact, the cheapest, Puente Genil in Fig. (3), was built for only € 7.2 million.

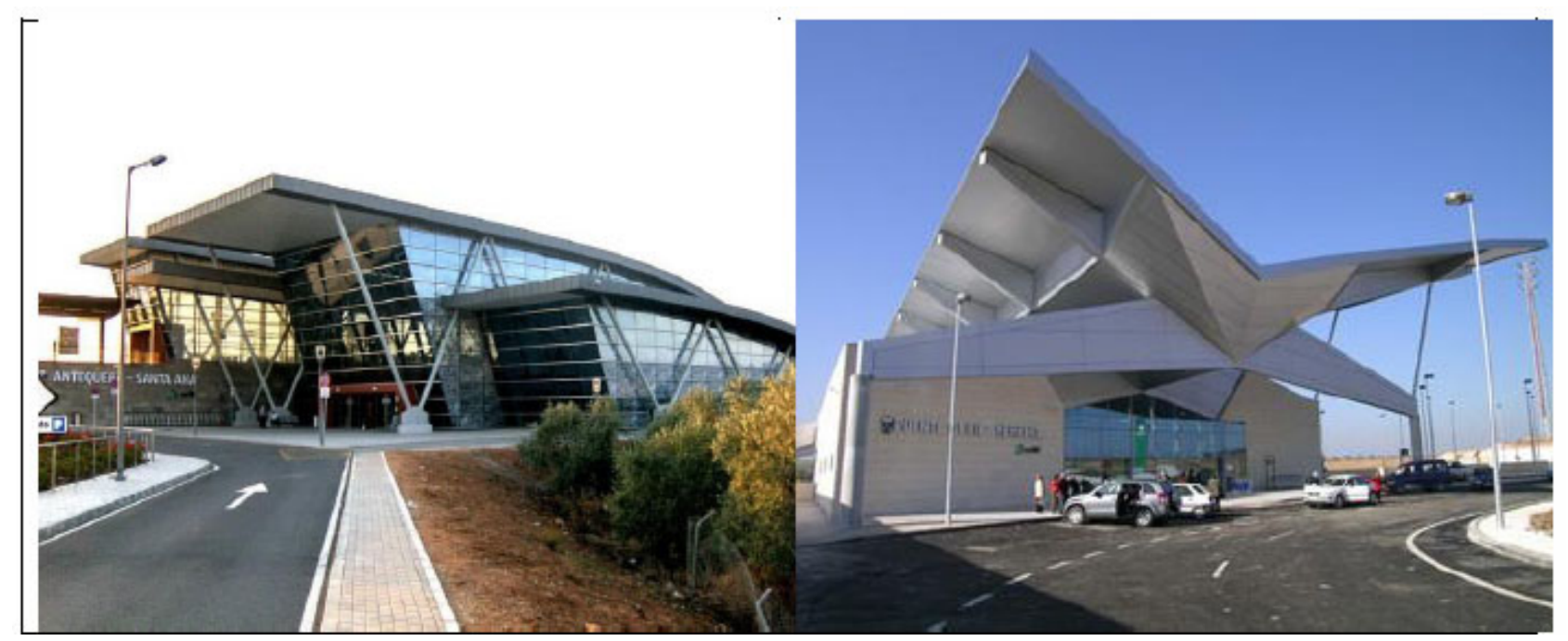

Fig. (3). Simple "halt stations" built at overtaking points: Antequera-Santa Ana and Puente Genil-Herrera.

One of the most interesting cases in this category is the newest peripheral station or (perhaps better) "halt" at Villanueva de Córdoba-Los Pedroches. It is located in a rural area with a very low population density which is near Córdoba and on the southern HSR line (1992) between Madrid and Seville. This area is badly connected by road, lacks conventional rail insfrastructure and with poor connections to the closest urban area of Córdoba which is around 70-80 $\mathrm{km}$ distance.

It was originally planned as a technical stop on the stretch of track between Puertollano and Córdoba, but then a 
local campaign began for it to be converted into a "halt". In 2009, the Junta de Andalucía (the autonomous regional administration), the Diputación Provincial de Córdoba (Local provincial administration) and the Mancomunidad de Municipios del Valle de los Pedroches (association of local councils) all agreed to pay for the renovation of the existing simple building (at a cost of $€ 2.7$ million) so that it could be used as a station or "halt". They also agreed to jointly fund work to improve its road accessibility. To do this, they signed an accord with ADIF (the Spanish rail administrator), which agreed to take responsibility for drafting the projects and managing the associated infrastructure. Delays in the execution of this work led to local collectives organising a number of protests to demand the delivery of the high-speed services promised for Los Pedroches. The media impact of these protests (which included human chains, blogs, a macro-concert, and campaigning train trips, etc.) produced the desired result when the new rail services began on $29^{\text {th }}$ March 2014.

In almost all of these cases, the implication of local and regional stakeholders played a very important role in obtaining intermediate stops, although this was not always enough to meet all of the demands associated with proposals for the introduction of new peripheral stations.

These simple "halt" stations contrast with the more complex stations that serve provincial capitals like Segovia and Cuenca or metropolitan areas like Camp de Tarragona. The Camp de Tarragona station is the most complex peripheral station structure, with a $6,000 \mathrm{~m}^{2}$ and a budget of $€ 40$ million. The station was officially opened in 2006 and, like some other contemporary Spanish HSR stations, it was initially conceived as an airport node that would give priority to managing passenger flows (see Fig. 4). However, the new station was eventually built $15 \mathrm{~km}$ from the city centre of Tarragona, at a site in the middle of nowhere, and with severe problems of accessibility. The number of commercial premises that currently remain closed inside the building clearly explains that this station serves more as a passing point than as a place to stay for any length of time. Other local capitals, like Segovia and Cuenca, also tend to have quite complex peripheral HSR station buildings that, as well as customer service facilities also tend to provide spaces for commercial services, most of which currently remain unused.

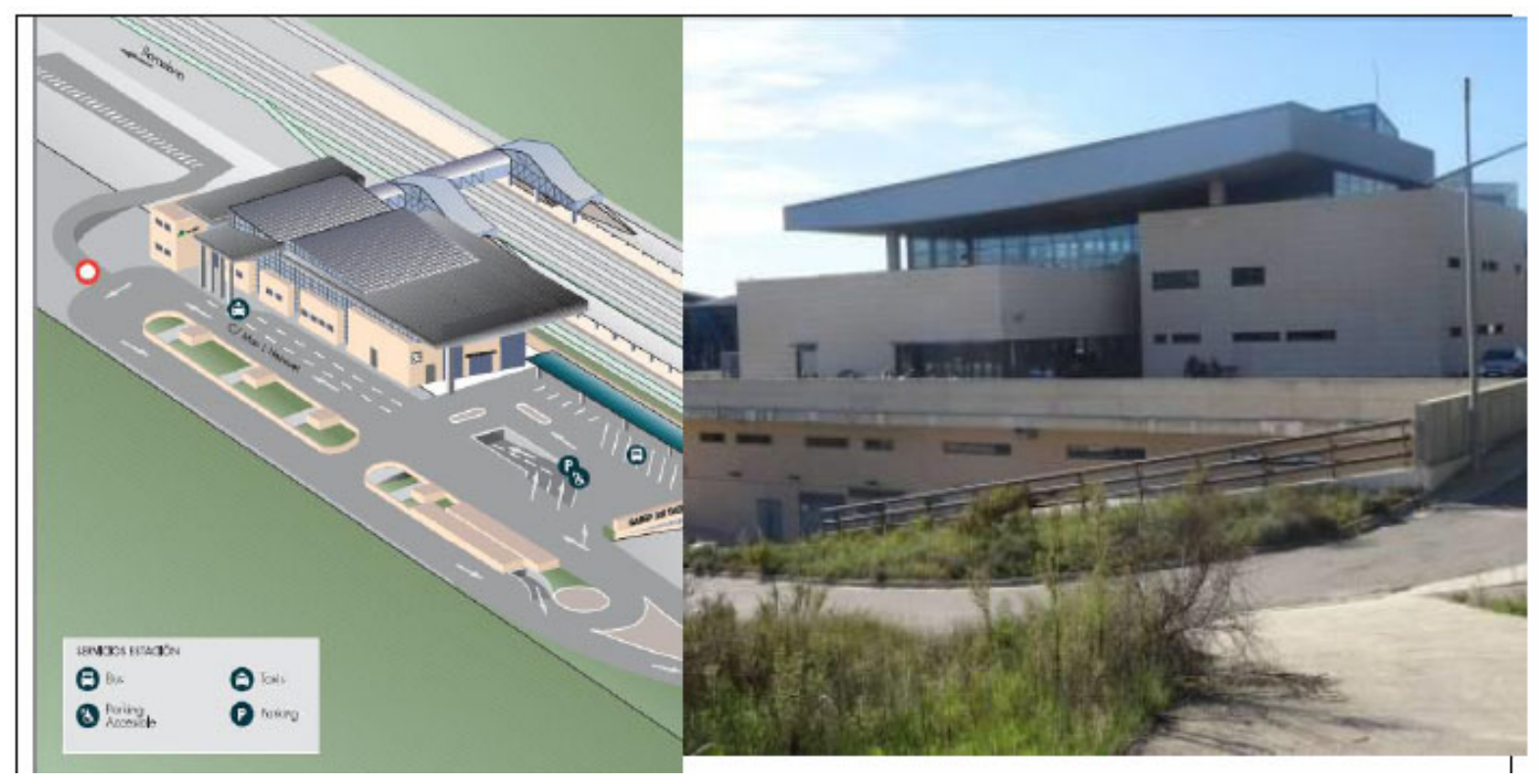

Fig. (4). The more complex structure of the Camp de Tarragona station building. Sources: Drawing on the left by ADIF; photo on the right by the author.

\section{A TYPOLOGY OF SPAIN's PERIPHERAL HSR STATIONS}

We have classified Spain's existing peripheral railway stations into four types (see Fig. 5). The first type corresponds to what the French call "gares-bis" [10 - 15]. They imply the construction of new HSR lines and stations that have no connection with the conventional railway network and are located at distances of between 5 and $10 \mathrm{~km}$ from the main urban nuclei. Examples of this typology in Spain include Segovia and Cuenca, which are the capitals of their respective provinces. The main challenges in these cases tend to concern how to integrate the new stations within the main urban nuclei. 


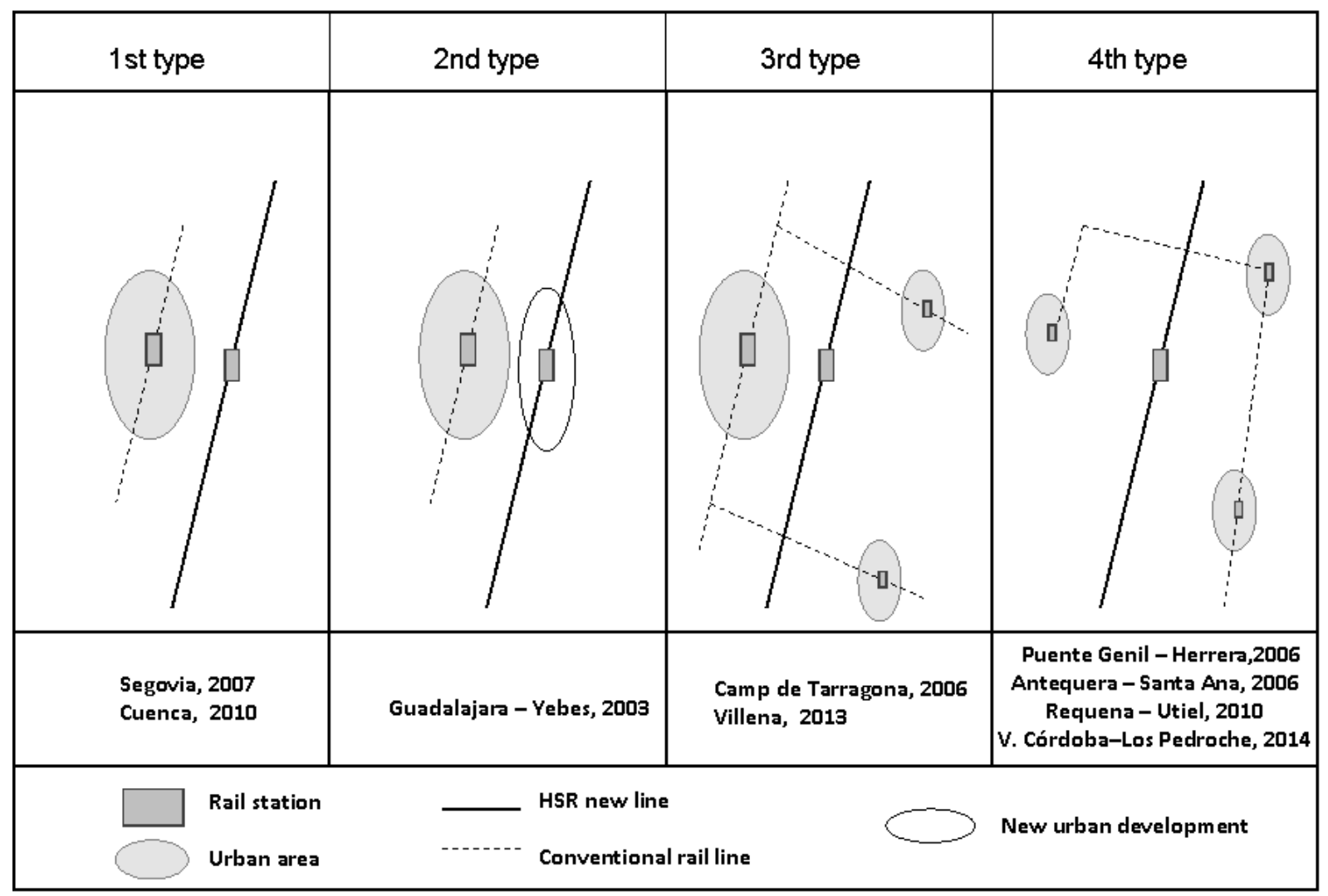

Fig. (5). A typology of peripheral HSR stations in Spain Source: author's own work.

The second typology may derive from the first, but the main difference between the two lies in the greater distances between these HSR stations and the main urban centres and the existence of other kinds of barriers (such as topographical obstacles) that act as obstacles to the urban integration of these station. This is the case of the peripheral station of Guadalajara-Yebes, which is located $10 \mathrm{~km}$ from the city centre of Guadalajara. This case is quite well known because of a large new property development that was initially planned around the station, and partially developed, which was supposed to give rise to a completely new city and generate a new urban and territorial structure.

A third typology is found where stations are located in multi-nuclear areas that are more or less densely populated. The main challenge here seems to be how to ensure that there is good accessibility between the station and the most populated surrounding nuclei. We find two different examples in this category: Camp de Tarragona, which was created to serve a small metropolitan area with a population of approximately 400,000; and Villena, which is in an industrial, multi-nuclear, area with small neighbouring cities and is located in the northwest of Alicante province (with a population of around 220,000 in the neighbouring comarcas (local districts) of Alto Vinalopó and Medio Vinalopó.

The fourth situation involves the creation of a peripheral station in a territory with a low population density and without any clear major urban polarities. In such cases, locating a simple station building (often referred to as a "stop" or "halt") at a previously designated overtaking point allows these territories to be served without having to make any significant modifications to the initial trajectories of their HSR lines. Examples of this can be seen at Antequera-Santa Ana, Puente Genil-Herrera, Requena-Utiel and Villanueva de Córdoba-Los Pedroches, which are all located in predominantly rural and agro-industrial areas with low population densities.

In almost all of these cases, the roles played by local stakeholders have been very important and help to explain the existence of these stations. This has been especially important in the fourth typology. Even so, this has not always been sufficient to solve all of the problems and meet all of the challenges that face stations in such peripheral locations. One particular weakness in such cases has, as we shall see, been the general inability to provide improved accessibility to the station and adequate public transport services to connect these stations with the settlements in their surrounding areas. In some cases, local and regional stakeholders have planned the development of industrial areas, logistical infrastructure and tertiary sector activities, but many of these have so far failed to materialise [14, 16, 17]. 


\section{PLANNING STRATEGIES AND URBAN ACTIONS AROUND PERIPHERAL STATIONS: THE MAIN CHALLENGES AND OPPORTUNITIES}

Planning strategies and urban actions undertaken at the local scale have mainly been related to specific territorial contexts and the particular characteristics of each station, with the latter seeking to take advantage of, and integrate, the new-found accessibility [14]. The accessibility associated with the new transport node tends to present a major challenge and one which has not always been very well resolved [15]. All of the cases studied tend to be associated with the creation of new points of road access and/or to involve making improvements to existing ones. In almost all of them, there is also a need to provide transport connections between the new station and the main urban nucleus via public bus services, but many of these have subsequently been cancelled on account of the stations receiving very little traffic $[7,17]$.

In the first scenario: that of a secondary station, the urban planning strategies employed have usually involved trying to integrate the new station into the existing urban structure by developing vacant land between the station and the city's urban centre. This strategy has been used, for example, in the cases of Cuenca and Segovia, as we shall now see.

In Segovia, which is a medium-sized provincial capital (with 77,000 inhabitants) that is not far from Madrid, the Master Plan (2007) foresaw the construction of nearly 18,000 new housing units, most of which were to be located to the south of the city in order to help integrate the station area within the main urban nucleus (see Fig. 6 on the right). Around the new HSR station, the Master Plan also foresaw the construction of commercial premises and other amenities that could take advantage of the newly created centrality. To date, however, nothing more has been developed than the new road infrastructure that links the station area to the city centre, while the new shuttle bus connection takes at least 20 minutes to reach the city centre, which is quite a long time if we consider that the train trip to Madrid takes only 28 minutes.

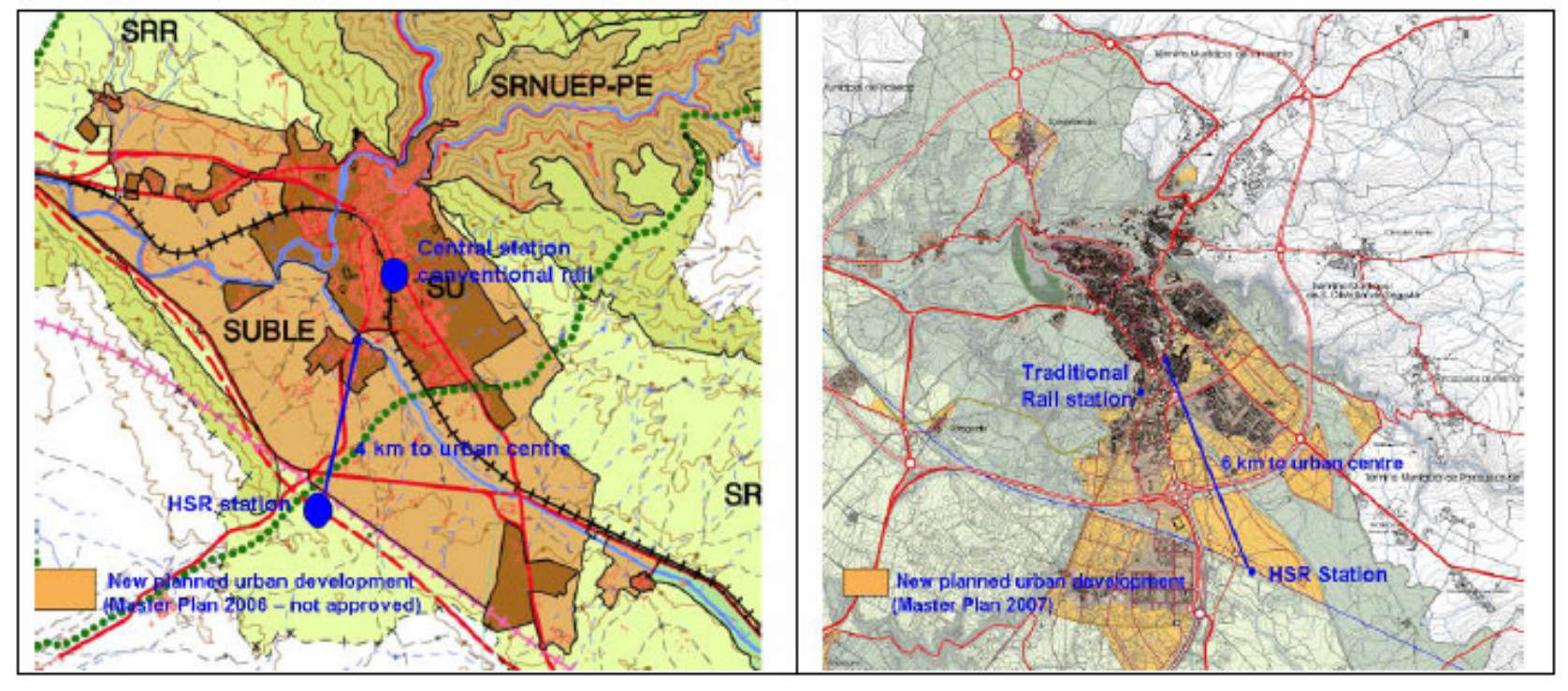

Fig. (6). Urban planning strategies developed in Cuenca and Segovia to integrate new station areas. Source: author's own work on town planning documents.

A second example is the case of Cuenca, which also has an independent, conventional rail link to a central station. Here, a Master Plan was presented in 2006, but has yet to be passed (see Fig. 6 on the left). This plan foresees a very ambitious urban development plan for the area between the city centre and the new station. New developments, mainly for residential uses, would permit a five-fold increase in the urban population, which is then forecast to rise from around 50,000 to almost 250,000 inhabitants.

In all peripheral stations, the main challenge facing planners and local authorities relates to accessibility. In most of these cases, new road infrastructure has been built to connect the urban centre to the station area, but problems of external accessibility have yet to be solved, with these stations often lacking adequate connections to the main motorway networks. Another important challenge facing stations belonging to this first typology relates to the provision of public transport services between the main urban nucleus and the peripheral station. Although the limited use of these 
rail services has made their respective shuttle bus services largely unsustainable, Segovia and Cuenca have, to date, maintained regular and coordinated shuttle services between their stations and city centres based on local railway timetables.

The main strategy deployed in the second typology, which is typified by Guadalajara-Yebes, is based on property development. In the case of Guadalajara-Yebes, this has involved the construction of more than 9,000 housing units around the peripheral station, projected in four different phases, for 30,000 new residents (Fig. 7). This large-scale property-based project was planned to create what would almost constitute a new city, which would not be far from the city centre of Madrid (only 20 minutes away by HSR). The ambitious urban development project was closely related to the Spanish property boom of the first decade of the $21^{\text {st }}$ century, but it was paralysed by the arrival of the economic crisis in 2008. In fact, this case has been presented in the international media as one of the clearest examples of the devastating effects of the bursting of Spain's property bubble. What is more, there is no shuttle connection between the new HSR station and Guadalajara's city centre because the route would be unsustainable given the very limited number of potential passengers. The existence of the station was the initial excuse to build an ambitious urban development project, but now the new inhabitants face many problems related to the lack of local services and amenities. Even so, the local council of the small municipality of Yebes, in which the majority of this development is located, seeks to continue with its original plan, which includes dedicating part of the land to industrial uses and economic activities.

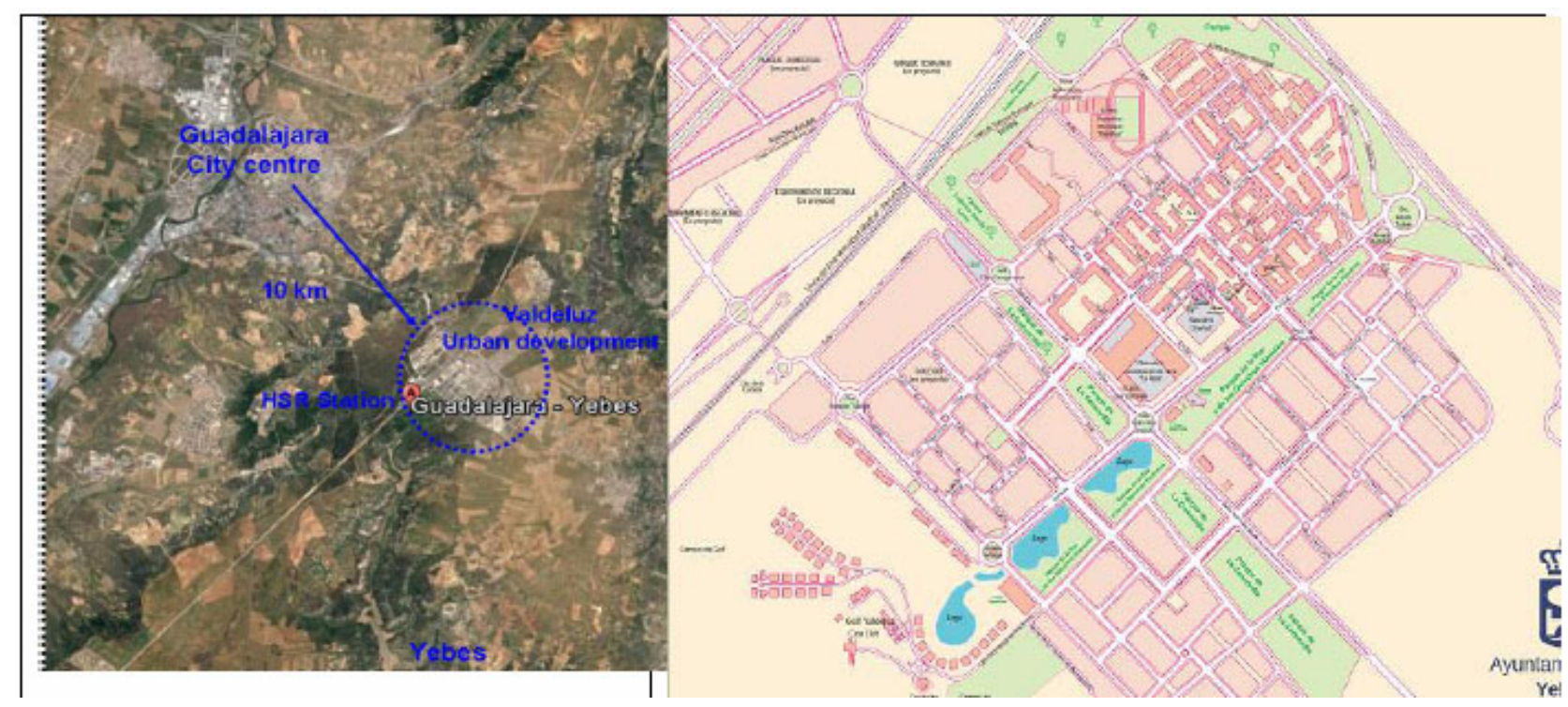

Fig. (7). The case of Valdeluz, around the Guadalajara-Yebes HSR station: an ambitious urban development project which has been paralysed by the economic crisis. Source: author's own work on the town, Google Earth image and local council map.

The third situation is typified by the Camp de Tarragona and Villena stations. The Camp de Tarragona station is located at quite a distance from the two main poles in what is an emergent metropolitan area: it is $15 \mathrm{~km}$ from the city of Tarragona, which has 133,545 inhabitants (2013), and $20 \mathrm{~km}$ from Reus, which had a population of 106,790 in 2013. The station was finally located between two relatively small municipalities (each with no more than 1,200 inhabitants) which have opted for very different development strategies and in a rather uncoordinated way. Plans have been made for a significant level of property development (affecting about 85 hectares) around the new station, with land being dedicated to social housing (950 housing units) and activities associated with the knowledge society and new technologies.

A second HSR station is also under construction in this area and will form part of the Mediterranean rail corridor, as seen in Fig. (8). The fact that this second station will be called the Central Station clearly highlights the peripheral role that the Camp de Tarragona HSR station plays in this area. The Camp de Tarragona station is not only distant from existing urban centres, but it is also not very well connected to the core of this emerging metropolitan area. Nevertheless, the station is quite well served in terms of the frequency of the shuttle bus services that connect it to the city of Tarragona and to the other nuclei in the metropolitan area. 


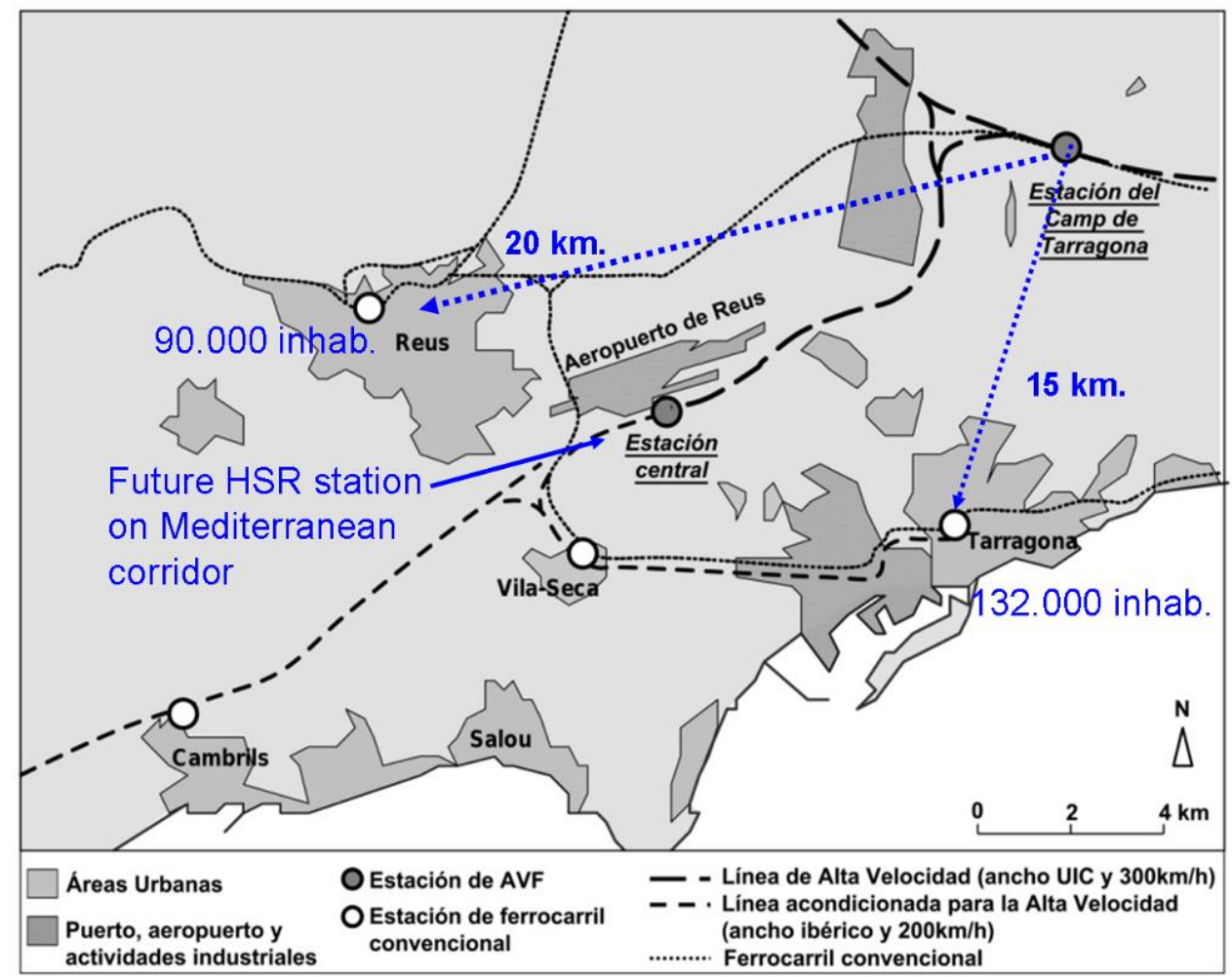

Fig. (8). The Camp de Tarragona HSR Station and its local area. Source: author's own work.

The case of Villena, which would also form part of this third typology, is quite different. Here, the station is much closer to the small municipality of Villena and its 34,530 inhabitants (2013), which is only $6 \mathrm{~km}$ away; it is also close to other nearby poles such as Elda (53,540 inhabitants) and Petrer (34,754 inhabitants). In this case, an industrial and logistical development project was initially planned, but this has yet to be approved. In this case, the HSR project was planned by the regional administration without local stakeholders playing more than very limited roles. It would, however, seem difficult to develop an area of economic activity of the type planned here in a place with such limited external accessibility and without access to the main motorway network. Providing a good level of collective transport has also been a problem in this case due the territorial structure, which is characterised by scattered nuclei and a low volume of population. In fact, a shuttle bus service was provided after the inauguration of HSR services in 2013 but has already disappeared on account of the very limited number of passengers who were using it.

In the fourth typology of peripheral stations located in rural and/or less densely populated areas, little has been planned to date and even less has been put into practice (see Fig. 9). At Antequera, Puente Genil-Herrera and RequenaUtiel, there were plans for industrial and logistical development projects and dry ports, but none of these have so far been either approved or materialised. All of these projects were planned by regional administrations without the active involvement of local stakeholders in anything other than merely testimonial roles. It would also seem difficult to develop areas of economic activity of the types initially planned at locations with such limited external accessibility.

Without a doubt, the most surprising project is that involving a test loop for developing new rolling stock technology which has been planned for Antequera. This project foresees the construction of a $55 \mathrm{~km}$-long stretch of track that would supposedly permit velocities of up to $520 \mathrm{~km} / \mathrm{h}$. It was planned by Spain's Central Government and is currently on standby because of a lack of public funding and while waiting for the possible appearance of private investment. This project has met strong opposition at the local scale, particularly on account of its potential environmental impact. The project currently remains alive, but it would require an investment of around $€ 400$ million in infrastructure. 


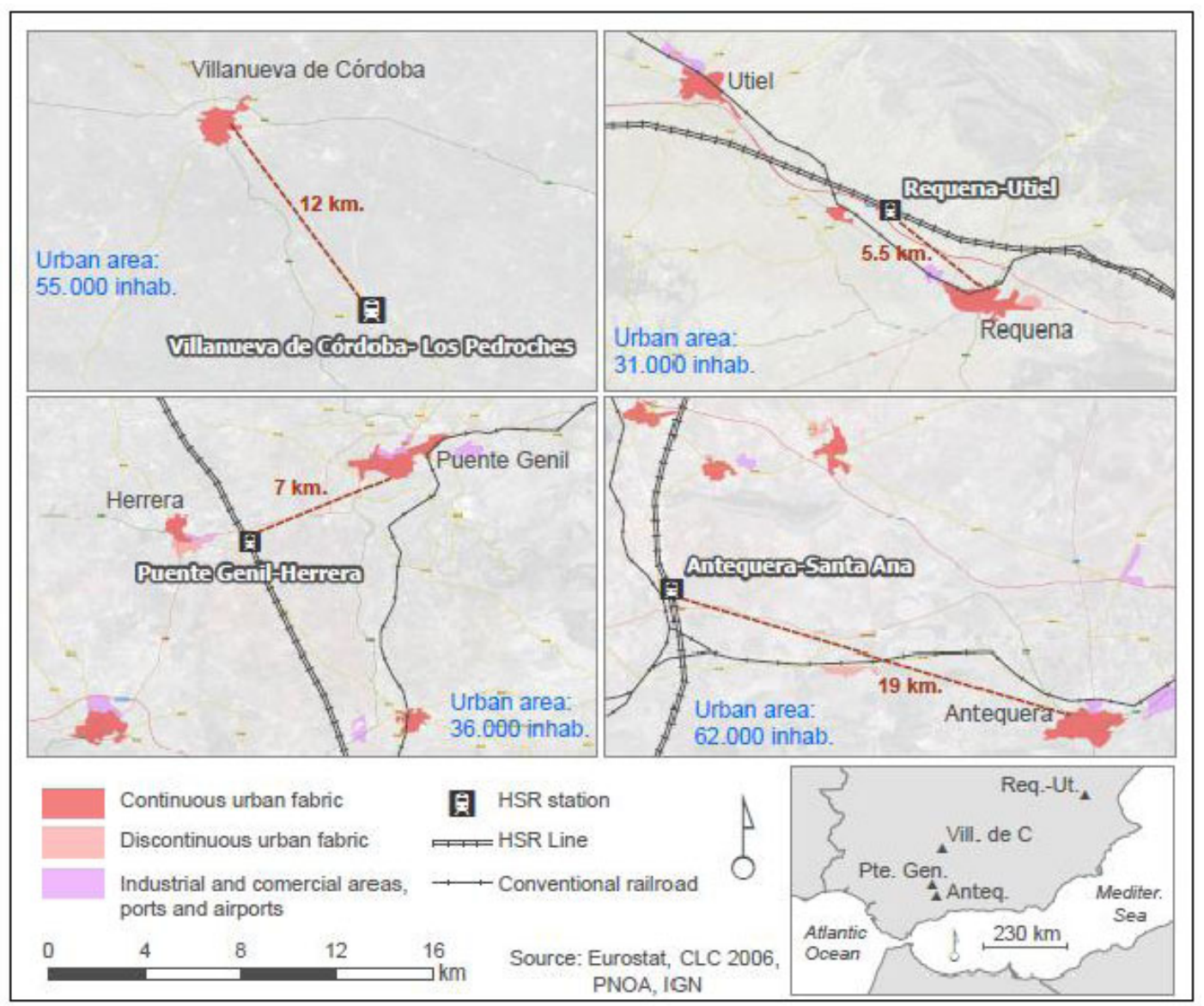

Fig. (9). Fourth typology: HSR in sparsely populated areas of Spain. Source: E. Olazabal, Department of Geography and Sociology, University of Lleida (Spain).

It is particularly difficult to provide collective transport services to this type of station. At Antequera-Santa Ana, Puente Genil-Herrera and Requena-Utiel, there are no buses or any other types of regular shuttle services to connect these stations to their neighbouring nuclei. In the cases of Antequera-Santa Ana and Requena-Utiel, such services were initially organised, but they were soon cancelled due to insufficient passenger numbers. At the last station to come into service: Villanueva de Córdoba-Los Pedroches (March 2014), the regional government has just provided a new shuttle bus service from the station.

\section{CONCLUSION}

The different histories behind these peripheral stations implantations within their respective territories are revealing about each case. To a large extent, these stations have been built as a result of pressure from local stakeholders, but they have ended up as stations that: are poorly integrated within their respective territories; suffer problems of poor accessibility; have poor or none existent collective transport services; and, in the majority of cases, have very few railway services. However, and as we have also shown, Spain's peripheral stations do not all share the same characteristics.

In Spain, different strategies have been developed around peripheral HSR stations. These have mainly been determined by factors such as: settlement structure, station location, local conditions and the positions adopted by stakeholders. Governance seems to be a fundamental issue in case of peripheral stations because they need coordinated actions to overcome the main challenges that confront them. However, as we have seen, in the majority of projects and plans there has been a general lack of coordination between different public administrations and an almost total absence of private-public cooperation.

One of the main challenges that has emerged in most of the cases studied, and which has yet to be overcome, concerns accessibility and connections to other transport modes; both internal and external accessibility still remain a 
problem waiting to be solved.

Finally, it should be noted that most of these projects were initially planned within a context of economic expansion and a boom in the property market and they therefore need to be reconsidered within the current context of crisis.

\section{CONFLICT OF INTEREST}

The author confirms that this article content has no conflict of interest.

\section{ACKNOWLEDGEMENTS}

Research financed by the Spanish Ministerio de Economía y Competitividad - Subdirección General de Proyectos de Investigación: Patrones de transformación urbana y estrategias asociadas a la alta velocidad ferroviaria en España (URBATAV) - CSO2012-34629

\section{REFERENCES}

[1] R. Vickerman, K. Spiekermann, and M. Wegener, "Accessibility and economic development in Europe", Reg. Stud., vol. 33, no. 1, pp. 1-15, 1999. [http://dx.doi.org/10.1080/00343409950118878]

[2] J.F. Troin, Rail et aménagement du territoire.. Edisud: Aix-en-Provence, 1995.

[3] J. Gutiérrez Puebla, "El tren de alta velocidad y sus efectos espaciales", In: Investigaciones Regionales, vol. 5. 2004, pp. 199-221.

[4] J. Ma Ureña, Ed., Territorial Implications of High Speed Rail: A Spanish Perspective, Ashgate. Aldershoot, 2012.

[5] V. Facchinetti-Mannone, C. Bellet, C. Ribalaygua, and C. Richer, Les petites agglomérations françaises et espagnoles face à la grande vitesse ferroviaire: comment convertir l'accessibilité en attractivité?. In: Cahiers Scientifiques des Transports, 2013 , pp. 3-31.

[6] B. Guirao, "Spain: highs and lows of 20 years of HSR operation", J. Transp. Geogr., vol. 31, pp. 201-206, 2013. [http://dx.doi.org/10.1016/j.jtrangeo.2013.05.010]

[7] C. Bellet, and J. Jurado, "La localización de las estaciones de alta velocidad ferroviaria en España", Anales de Geografía, vol. 34, no. 2, pp. 9-24, 2014.

[8] M. Garmendia, J. Ma Ureña, and C. Ribalaygua, "High speed rail: implication for cities", Cities, vol. 29, pp. S26-S31, 2012. [http://dx.doi.org/10.1016/j.cities.2012.06.005]

[9] V. Facchinetti-Mannone, and J.J. Bavoux, L'implantation des gares TGV en France: tensions interscalaires, jeux d'acteurs et recompositions spatiales. in Belgeo, 2010, no. 1-2, pp. 9-22.

[10] J.F. Troin, "Les gares T.G.V. et le territoire: débat et enjeu", Ann. Georgr., vol. 593-594, pp. 34-50, 1997. [http://dx.doi.org/10.3406/geo.1997.20764]

[11] S. Zemp, M. Stauffacher, D.J. Lang, and R.W. Scholz, "Classifying railway stations for strategic transport and land use planning: Context matter!", J. Transp. Geogr., vol. 19, pp. 670-679, 2011. [http://dx.doi.org/10.1016/j.jtrangeo.2010.08.008]

[12] L. Bertolini, "Nodes and places: complexities of railway station redevelopment", Eur. Plann. Stud., vol. 4, no. 3, pp. 331-345, 1996. [http://dx.doi.org/10.1080/09654319608720349]

[13] C. Bellet, P. Alonso, and A. Casellas, "Infraestructuras de transporte y territorio. Los efectos estructurantes de la llegada del tren de alta velocidad en España", Bol. Asoc. Geogr. Esp., vol. 52, pp. 143-163, 2010.

[14] C. Ribalaygua, "Alta velocidad y ciudad: estrategias de incorporación de las nuevas estaciones periféricas francesas y españolas", In: Cuadernos de Investigación Urbanística, 42. Instituto Juan de Herrera, Universidad Politécnica de Madrid: Madrid, 2004.

[15] V. Facchinetti-Mannone, Location of High Speed Rail Stations in French Medium-Size City and Their Mobility and Territorial Implications, 2012.

[16] C. Bellet, P. Alonso, and A. Gutiérrez, "The high-speed rail in Spanish cities: Urban integration and local strategies for socio-economic development", In: J.Ma Ureña, Ed., Territorial implications of high speed rail. A Spanish perspective. Ashgate Publishing, t: Aldershoot, 2012, pp. 163-196.

[17] A. Ortuño, D. Bautista, P. Fernandez, and E. Libourel, "High-speed Train Territorial Impact in French and Spanish Medium Cities with Stations Located in the Outskirts", In: paper presented at Transport Research Arena 2014, 14th-17th April, 2014 , Paris.

(C) Carmen Bellet; Licensee Bentham Open.

This is an open access article licensed under the terms of the Creative Commons Attribution-Non-Commercial 4.0 International Public License (CC BY-NC 4.0) (https://creativecommons.org/licenses/by-nc/4.0/legalcode), which permits unrestricted, non-commercial use, distribution and reproduction in any medium, provided the work is properly cited. 